\title{
Total SciComm: A Strategy for Communicating Open Science
}

\author{
Manh-Toan Ho *D, Manh-Tung Ho (D) and Quan-Hoang Vuong (D) \\ Centre for Interdisciplinary Social Research, Phenikaa University, Hanoi 100803, Vietnam; \\ tung.homanh@phenikaa-uni.edu.vn (M.-T.H.); hoang.vuongquan@phenikaa-uni.edu.vn (Q.-H.V.) \\ * Correspondence: toan.homanh@phenikaa-uni.edu.vn
}

check for updates

Citation: Ho, M.-T.; Ho, M.-T.; Vuong, Q.-H. Total SciComm: A Strategy for Communicating Open Science. Publications 2021, 9, 31. https://doi.org/10.3390/ publications 9030031

Academic Editors: Pilar Mur-Dueñas and Rosa Lorés

Received: 4 June 2021

Accepted: 20 July 2021

Published: 22 July 2021

Publisher's Note: MDPI stays neutral with regard to jurisdictional claims in published maps and institutional affiliations.

\begin{abstract}
This paper seeks to introduce a strategy of science communication: Total SciComm or all-out science communication. We proposed that to maximize the outreach and impact, scientists should use different media to communicate different aspects of science, from core ideas to methods. The paper uses an example of a debate surrounding a now-retracted article in the Nature journal, in which open data, preprints, social media, and blogs are being used for a meaningful scientific conversation. The case embodied the central idea of Total SciComm: the scientific community employs every medium to communicate scientific ideas and engages all scientists in the process.
\end{abstract}

Keywords: preprints; open science; science communication; social media; Total SciComm

\section{Introduction}

Growing skepticism towards scientific findings makes capturing attention from the public an urgent and serious issue for scientists. The attention will help raise the scientists' profiles and provide scientists a channel to communicate through scientific ideas. On YouTube, and a new form of radio-podcast-the rise of the Intellectual Dark Web group is a prominent example of an effort for good and effective science communication [1]. However, mainstream science communication is still limited to conventional media like journalism or personal blog. In a world where "information strategy" is becoming more important [2,3], science communication needs to employ every tool possible.

The rise of social networking sites has coincided with a sharp decline in public trust in science. In 2016, only $21 \%$ of American adults reported a great deal of confidence in scientists. The ineffectiveness in communicating scientific truth to the public has traditionally been argued to result from the lack of ability of scientists. However, in a post-truth society [4], the core of the problem has now shifted toward the sheer availability and the contagion of misinformation and disinformation in modern digital media [5]. Improving public communication of scientific truth and combatting fake news are two sides of a coin in the vital battle to improve public epistemology. Society's failure to agree on a basic set of facts has been deadly, as shown in the COVID-19 pandemic [6]. While scientists are trained to think in abstract and statistical terms, the pandemic has revealed that humans have not evolved to seek a correct understanding of reality [7]. Rather, as shown in decades of research in evolutionary psychology and behavioral economics, humans are predisposed by evolution to have weak intuition about risks, to be prone to self-deception, to harbor confirmation bias, among many of our inherent and systemic flaws. Thus, the mission of scientific communication is not merely about presenting cold, scientific findings but also about how to generate healthy engagement with these facts [8] and prepare society for future threats with a more robust epistemological stance.

There have been multiple proposals and academic journals devoted to studying and advocating for innovative approaches in science communication [8-12]. For example, studying the success of Nerd Nite, which started as a series of informal scientific talks in a local pub in Brooklyn then spread to more than 100 cities in the world, Tan and Perucho (2018) propose that to reach a wider audience, scientists must bring science to the 
people rather than let the people come to them. This means to rethink current outreach programs to focus on where the target audiences already are [9]. Contera (2021) reflects on science's central mission of public communication and proposes that to communicate a scientific story effectively, a scientist must: (1) investigate the origins; (2) disclose his/her plan and position; (3) inspire the audience and herself; (4) explore positive scenarios; (5) examine unintended consequences; (6) adapt one's language; (7) and contribute to the democratic process [8]. In a similar vein, Matta (2020) argues that science communication can be a preventive tool for future pandemics if science is effectively communicated by embracing interdisciplinary research, crafting an accessible narrative, making the science personal, and galvanizing citizen participation in the scientific process [13]. Indeed, it takes a huge amount of effort to get scientific facts across without backfiring. This entails an effective science communication strategy is to understand how to generate scientists willingness and how the backfire effect happens. Besley et al. (2018) found that beliefs in public science communication make a difference, and self-confidence in communication skills make scientists more willing to engage. Thus, Besley et al. suggest it is worth showing the scientists results of their engagement efforts to enhance their willingness for public engagement [14]. To maximize the effectiveness of science communication, Friesen, Van Stan, and Elleuche (2018) suggest a framework to present the complexity of science in a friendly comic [10]. Peter and Koch's (2015) work on the backfire effect shows that bringing up a scientific myth to correct it might be a counterproductive strategy as people tend to misremember it as correct. However, if the backfire effect is reduced, people are asked to form an immediate judgment upon receiving the correct information [12].

As proposals to improve the effectiveness of scientific communication are diverse, this article proposes a unifying strategy for science communication, which is called Total SciComm or All out science communication. The strategy is total in three senses. First, the core idea of this strategy is to utilize every possible media to communicate every aspect of science. Second, to efficiently explore and use those media techniques, the scientific community must deploy all of its rigors and sophisticated methods to study what makes science communication effective. Third, similar to the Dutch's total football, scientists must acquire more skills and stamina for public engagement to implement the new science communication strategy. The next section will use a debate surrounding a high-profile case of a now-retracted Nature's article to illustrate how scientists communicate science in the open-access era. Then, we will explain the Total SciComm strategy in detail and how it can help expand the outreach of science.

\section{The Seshat Debate}

In March 2019, Nature published a study named "Complex societies precede moralizing gods throughout world history" [15]. For disclosure, the study was retracted on 7 July 2021, which we will go over in more detail [16]. The study presented a striking result that when the society developed in a complicated way, the role of moralizing gods became more apparent [15]. The study resulted from learning about the "moralizing gods" hypothesis with the large historical dataset Seshat. This hypothesis suggested that the belief in being judged by higher power would be a cultural continuation to control a large, complex development society. The scale of Seshat and sensational results instantly caught the public's attention, with Science or ScienceDaily covering the new findings $[17,18]$.

Because of the open dataset, other research teams were able to re-analyze the initial results. Just two months after the original research was published in Nature, a critical review was posted by Bret Beheim and his collaborators on PsyArXiv on 2 May 2019 [19]. This manuscript stated that some factors of data processing and analysis methods had influenced the conclusions of the original publication. In retrospect, moralizing gods appeared before complex societies. One day after the critical paper of Beheim et al. [19], another manuscript from Slingerland et al. also showed concern about the encryption process to the amount of historical data [20]. 
The corresponding author of the study on moralizing gods responded to the critical analysis of Beheim and his partners shortly after that, on 5 May 2019, with a blog posted on Nature Ecology and Evolution Community [21]. The Seshat team intended to publish a formal rebuttal [22] to Beheim et al. [19]; however, the preprint was withdrawn. On the same day, veteran researchers Harvey Whitehouse and Pieter Francois, the founding directors of Seshat Databank (with Peter Turchin), also shared their opinions regarding the criticisms on a blog post [23]. Bret Beheim also used his blog to discuss further the technical problem of the moralizing gods paper [24].

To respond to the criticism of Slingerland in [20], a rebuttal and an introductory paper from the Seshat team were expected to be published in the Journal of Cognitive Historiography altogether. However, it was not until November 2020 that all three articles, the Slingerland et al.'s criticism, the rebuttal, and the introductory paper of the Seshat database, were finally published [25-27]. Back in 2019, with the editorial permissions, the Seshat team posted the Slingerland rebuttal and the introduction of the Seshat dataset on SocArXiv [28,29].

In November 2019, the Seshat team uploaded another paper [30] to SocArXiv to test the other hypotheses related to the relationship between social complexity and moralizing religions, previously explored in the now-retracted Nature paper $[15,16]$.

After that, the debate had supposedly died down. There are official publications on the Journal of Cognitive Historiography of the SocArXiv preprints. However, there was no concrete evidence to suggest that the debate will arrive at a final conclusion. Until 7 July 2020 (which was when this paper was under review), Nature published two articles concerning the retraction of "Complex societies precede moralizing gods throughout world history": a Matter Arising article from Bret Beheim and his colleagues [31] and the retraction notice [16].

The Matter Arising article from Beheim et al. [31] is the peer-reviewed version of the first criticism [19] toward the moralizing gods paper. Meanwhile, the retraction notice, which was written by the Seshat team, concluded that there are issues with the data treatment. Even though there was still evidence for the original argument, the reanalysis suggested substantial differences that warranted retraction. The retraction notice also pointed to two other preprints that contain new analyses, and one was the preprint published in November 2019 [30], another preprint was published in April 2021 [32]. The April 2021 preprint suggested that the editors requested the retraction, and the manuscript itself is a serious effort in revising and fixing the mistake.

The chronology of this entire debate is summarized in Figure 1:

First of all, we need to talk about the role of data and statistical analysis in the current humanities literature. According to Whithouse and Francois [23], data and statistics will help validate many long-standing theories in the humanities and push the boundaries of the disciplines. Data encryption and database construction can help to test historical theories, limit bias, and offer a unique perspective. In addition to the Seshat data, other studies have utilized ageless data sources such as folktales [33,34] and 20th-century house façades [35] to provide evidence for cultural phenomena. The open data movement and new guidelines such as the FAIR principles [36] are crucial for this trend to continue.

At the same time, datasets, collection methods, and data analysis are also widely deposited to Open Science Framework, Harvard Dataverse, Zenodo, and other repositories, allowing scientists to examine research results. Two critical reviews, respectively led by Bret Beheim and Edward Slingerland [19,20], are prime examples. They meticulously examined the process of data encryption and database construction to refute Seshat's research results.

To ensure the progress, they also took advantage of the preprint systems to bring their concerns to the public as quickly as possible. The rebuttal of the original research authors was also posted on the blog site for the prompt response. However, the dispersion of manuscripts on different systems was also confusing for readers. It is even possible to create the impression that the results of the unapproved preprint are accurate. Notably, the slow responses from the journals, which took one year (in the case of Journal of Cognitive Historiography) or two years (in the case of Nature) to provide official publications, did not contribute meaningfully to the debate [37]. 


\section{The Story of}

\section{The Seshat Debate}

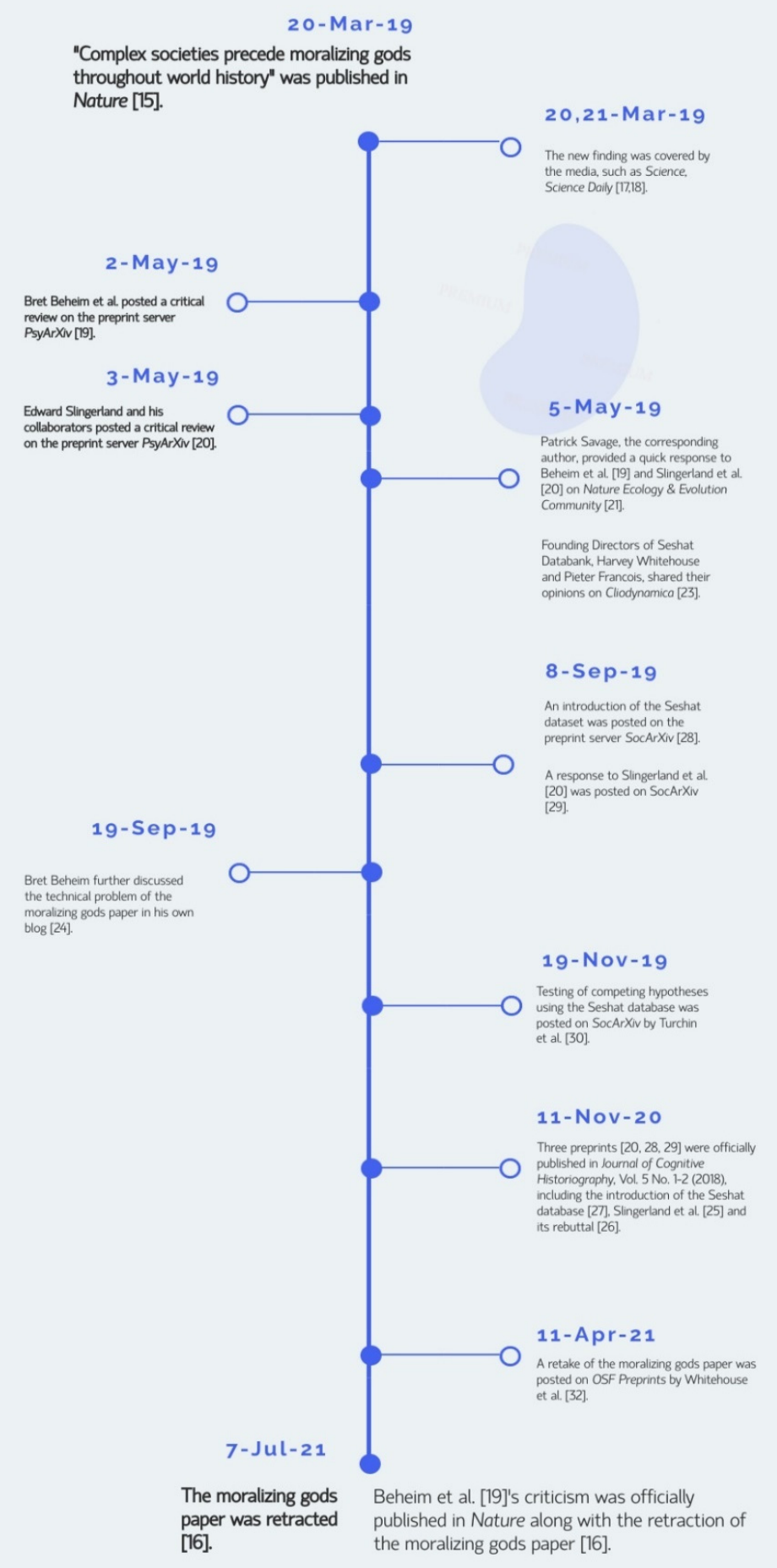

Figure 1. The chronology of the Seshat debate [15-21,23-30,32]. 
Besides the preprints system or blog sites, social networks like Twitter are also used to share formal critical articles, help researchers give some direct perspectives and directly address the subject of exchange. On Twitter, researcher Patrick Savage also made his point about this debate: a highly constructive dialogue representing the open science age [38]. Chris Kavanagh, a cognitive anthropologist at the University of Oxford, also appreciates the scientists' spirit of communication and frank criticism [39]. When posting on Twitter about the Seshat group's responses on SocArXiv, author Patrick Savage has directly tagged other scientists into his post. Many scientists even made their assessments on Twitter, such as researcher Richard McElreath's graph of moral deities based on Seshat data [40]. Furthermore, after two years without any update, Twitter allowed us to know about the retraction. Through tweets from Bret Beheim, Patrick Savage, and other scientists, the retraction notice was not buried under other pressing matters.

\section{Total SciComm}

Scientists involved in the Seshat debate have used a wide variety of media to communicate their concerns and responses. Preprints, social media, and blogs were used to spread the message across. Their flexible use of communication tools has provided a lively debate of scientific ideas and sensational findings. While the debate is largely internal, various aspects could be communicated to the public via different media.

In 1974, Netherlands went to the FIFA World Cup final and introduced Total Football (or Totaalvoetbal), a tactical system that has become the identity of Dutch football [41]. Total Football aims to exploit the football field's space through the fluidity of movements and the interchangeability of players' positions [42,43]. Its core philosophy has been inherited and continuously evolved by its disciples, such as Marcelo Bielsa or Pep Guardiola [41-44]. The attractiveness of Total Football lies in the combination of both aesthetic and effectiveness on the field. The style requires a deep understanding of positions and movements and perfection in basic techniques.

Inspired by the philosophy of Total Football, we would like to propose a strategy to do science communication called Total SciComm. Total SciComm uses every form of the media to communicate sound scientific ideas and engage all scientists in the process in its simplest form. However, just as Total Football demands perfection of the basics, Total SciComm demands a comprehensive understanding of the scientific process, total effectiveness in employing different media types to communicate science, and total honesty in science communication.

As open science has slowly become the new standard for modern science, the strategy is expected to provide total transparency in science communication. In return, the transparency to the public would help the communication be more efficient [45] and mitigate the potentially harmful effect of scientific retraction [46]. An early model of the Total SciComm strategy is presented in Figure 2:

Essentially, the Total SciComm strategy means using every medium to communicate science. In the Seshat debate, the conventional communication tools that are available were used effectively by the scientists. Traditional news media disseminated the main findings $[17,18]$. Preprints were used for rebuttal $[19,20]$, while blogs were used for both rebuttal [21] as well as providing personal opinions [23]. Similarly, social media were used for quick public discussion.

These media were all included in Figure 2. However, we argue that there are other media that scientists should also utilize. The main goal is to bring science to a wide range of audiences, including scientists, policymakers, and the public. The differences in means of communication provide scientists with more ways to explain their ideas and results and reach audiences. For examples:

Scientific novel: human beings are a storytelling species, and storytelling is a powerful tool for scientists. Indeed, scientific research is often dry and technical, but significant findings can be translated into a narrative. For instance, Amanda C. Niehaus-a biologisthas written several novels and short stories based on her research. According to her own 
experience, unlike the certainty of research, writing fiction lets her explore new possibilities and come up with new ideas [47]. Moreover, there are well-developed methodologies to translate scientific results into a visual novel format [10].

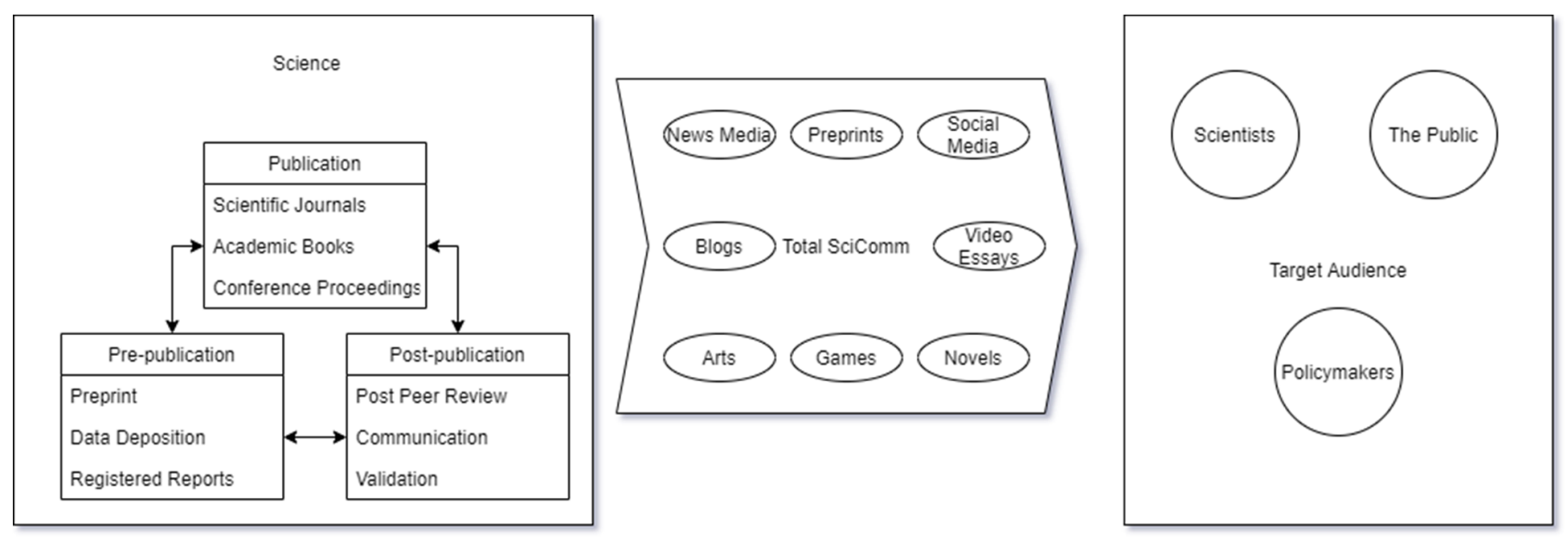

Figure 2. A preliminary model of the Total SciComm strategy.

Scientific film and video: on YouTube, crash course videos or lecture videos have received many views [48-51]. They are usually short but have a strong visual animation to support the explanation. As a more established art form, a film can suffer from the artistic expression of the filmmaker. Nonetheless, the ability to visualize a scientific concept is their strength. Classic science fiction such as Blade Runner (1982) [52] or 2001: A Space Odyssey (1968) [53] utilizes scientific ideas and philosophical discussions. Nowadays, scientific journals have accepted video abstracts, providing another useful way to communicate the research.

Scientific game: the gaming market reached a value of US $\$ 167.9$ billion in 2020 [54]. The interactive gaming experience has become an important part of our popular culture. In the scientific community, scientists are testing board games or indie games to teach children scientific concepts [55]. Gamers even helped find a solution for the AIDS puzzle through a science puzzles game [56]. Recent studies also suggested the untapped power of using video games to raise pro-environmental awareness [57]. The scientific concept and gaming experience can also introduce the life and experiences of a scientist. The interactive nature of video games is especially useful in explaining various difficult and rigorous aspects of science: research design, concepts, inference standards, or methods. For instance, the Seshat database is a complicated data collection project that took several years to complete $[27,28]$. Scientists can understand the data collection process, but gamification of the data collection process might help the public understand science better.

Scientific art: artists have communicated abstract ideas for generations. However, artistic expression sometimes strays too far away from the scientific truth. It does not mean that art is unable to combine both artistic expressions and scientific ideas. From September 2018 to January 2019, Science Gallery London introduced an art exhibition exploring the concept of addiction [58]. Scientists and artists are searching for aesthetics, and there have been great artists who are scientists too.

While the idea sounds simple, its practicality can be challenging, especially with highly technical aspects such as methods. The challenge in using these media also lies in their high entry point. While writing a blog can be done easily, making a video requires scientists to possess various tools and skills. Essentially, while scientists are skillful in telling a scientific story in the traditional scientific publication format, adopting different formats is still uncommon, which is more of an add-on rather than a serious endeavor [11]. The difficulty in mastering different media formats might be some obstacles scientists must overcome. Yet, such uncharted territory offers not only unique strengths to communicate 
different aspects of science but fertile grounds for scientific ideation, collaboration, and even business [59].

Moreover, when social media are magnifying misinformation and fake news, the usage of different media needs serious quality control. First and foremost, the Total SciComm strategy should be used on verified and peer-reviewed scientific results. The Total SciComm strategy will only work when the science is sound. This principle must not be compromised. Secondly, different forms of media have their own market functions. Thus, these functions should be utilized to become the second guard against misinformation, fake news, and other issues. For instance, films, video games, or arts have professional reviewers. In platforms with a social media nature like YouTube, the views, likes, dislikes, and the community itself are viable options for safeguarding quality.

\section{Science Communication in the Open Science Era}

In an age of open science, a peer-reviewed research paper could still face negative responses and criticism from colleagues. The academic exchange will no longer be under the veil of anonymity, but the scientists can now express their opinions freely through preprints or even social networks. In return, their opinions will also be publicly scrutinized. Thus, the need for effective science communication is more pressing than ever, especially during the COVID-19 pandemic [13]. MIT Physicist Max Tegmark has argued that the lack of active participation from the scientific community in communicating their ideas is dangerous for society's sustainability of society [60]. Moreover, lacking proper scientific communication, together with the lack of transparency, is a major reason why the public lacks a healthy perspective on the cost of doing science [61].

This paper proposes the Total SciComm strategy, which means the scientific community uses every medium to communicate science. While news articles, blogs, or preprints can reach the public in a conventional manner, films, video games, or arts can help embedded scientific ideas on a cultural level. Like how a football coach with the total football philosophy must adapt to the specific circumstances of each match and innovate to maximize the winning chance, the scientific community must also adapt and innovate their Total SciComm tactics to their circumstances. As new scientific ideas are always challenging, deep-rooted cultural factors can vastly influence how the general public adds these ideas to their worldview.

The paper has proposed a new metaphor to help shape strategic thinking in science communication: Total SciComm. Indeed, the scientific community has now increasingly engaged with the wider public utilizing more diverse communication tools and channels, yet, we believe there is a need for an umbrella term and a unique metaphor to capture the totality of the work of engaging the public with science. While we have presented the strategy with different examples, we acknowledge that there are still limitations [46]. First, this paper is not an empirical study. We rely on a specific case and various anecdotal evidence to propose the new strategy of science communication. Thus, there might be various aspects that need to be debated, tested, and falsified. Second, we used only one case to maintain the focus of our paper, which is to explain and discuss the core ideas of Total SciComm. Certainly, the Total SciComm strategy can be illustrated with different examples. Thus, we hope to address these issues in future research studies.

Author Contributions: The authors contributed equally to the intellectual discussion underlying this paper, literature exploration, writing, reviews and editing, and accept responsibility for the content and interpretation. All authors have read and agreed to the published version of the manuscript.

Funding: This research received no external funding.

Data Availability Statement: Not applicable.

Acknowledgments: The authors would like to show their appreciation to members of the Centre for Interdisciplinary Social Research, Phenikaa University, including Nguyen To Hong Kong, Nguyen Minh Hoang, La Viet Phuong, Le Tam Tri, Nguyen Thanh Thanh Huyen. 
Conflicts of Interest: The authors declare no conflict of interest.

\section{References}

1. Weiss, B. Meet the Renegades of the Intellectual Dark Web. Available online: https://www.nytimes.com/2018/05/08/opinion/ intellectual-dark-web.html (accessed on 21 July 2021).

2. Arquilla, J.; Ronfeldt, D.F. Netwar Revisited: The Fight for the Future Continues. Low Intensity Confl. Law Enforc. 2002, 11, 178-189. [CrossRef]

3. Mantello, P.; Ponton, D. Breaking point: Mapping the politics of extreme otherness in right-wing media of Brexit and the Refugee Crisis. In The Challenges of Migration in North America and Europe: Comparing Policies and Models of Reception; Rotella, S.G., Ed.; Forum Italicum Publishing: New York, NY, USA, 2018; pp. 65-87.

4. McIntyre, L. Post-Truth; The MIT Press: Cambridge, MA, USA, 2018.

5. Iyengar, S.; Massey, D.S. Scientific communication in a post-truth society. Proc. Natl. Acad. Sci. USA 2019, 116, 7656-7661. [CrossRef]

6. Pearson, H. How COVID broke the evidence pipeline. Nature 2021, 593, 182-185. [CrossRef]

7. Seitz, B.M.; Aktipis, A.; Buss, D.M.; Alcock, J.; Bloom, P.; Gelfand, M.; Harris, S.; Lieberman, D.; Horowitz, B.N.; Pinker, S.; et al. The pandemic exposes human nature: 10 evolutionary insights. Proc. Natl. Acad. Sci. USA 2020, 117, 27767-27776. [CrossRef] [PubMed]

8. Contera, S. Communication is central to the mission of science. Nat. Rev. Mater. 2021, 6, 377-378. [CrossRef] [PubMed]

9. Tan, S.Z.K.; Perucho, J.A.U. Bringing Science to Bars: A Strategy for Effective Science Communication. Sci. Commun. 2018, 40, 819-826. [CrossRef]

10. Friesen, J.; Van Stan, J.T.; Elleuche, S. Communicating Science through Comics: A Method. Publications 2018, 6, 38. [CrossRef]

11. Rodríguez Estrada, F.C.; Davis, L.S. Improving Visual Communication of Science Through the Incorporation of Graphic Design Theories and Practices Into Science Communication. Sci. Commun. 2015, 37, 140-148. [CrossRef]

12. Peter, C.; Koch, T. When Debunking Scientific Myths Fails (and When It Does Not): The Backfire Effect in the Context of Journalistic Coverage and Immediate Judgments as Prevention Strategy. Sci. Commun. 2016, 38, 3-25. [CrossRef]

13. Matta, G. Science communication as a preventative tool in the COVID19 pandemic. Humanit. Soc. Sci. Commun. 2020, 7, 159. [CrossRef]

14. Besley, J.C.; Dudo, A.; Yuan, S.; Lawrence, F. Understanding Scientists' Willingness to Engage. Sci. Commun. 2018, 40, 559-590. [CrossRef]

15. Whitehouse, H.; François, P.; Savage, P.E.; Currie, T.E.; Feeney, K.C.; Cioni, E.; Purcell, R.; Ross, R.M.; Larson, J.; Baines, J.; et al. RETRACTED ARTICLE: Complex societies precede moralizing gods throughout world history. Nature 2019, 568, $226-229$. [CrossRef] [PubMed]

16. Whitehouse, H.; François, P.; Savage, P.E.; Currie, T.E.; Feeney, K.C.; Cioni, E.; Purcell, R.; Ross, R.M.; Larson, J.; Baines, J.; et al. Retraction Note: Complex societies precede moralizing gods throughout world history. Nature 2021, 595, 320. [CrossRef] [PubMed]

17. Science Daily Complex Societies Gave Birth to Big Gods, Not the Other Way Around. Available online: https: / /www.sciencedaily. com/releases/2019/03/190320141116.htm (accessed on 29 June 2021).

18. Wade, L. Did judgmental gods help societies grow? Science 2019, Preprint. [CrossRef]

19. Beheim, B.; Atkinson, Q.; Bulbulia, J.; Gervais, W.; Gray, R.; Henrich, J.; Lang, M.; Monroe, M.; Muthukrishna, M.; Norenzayan, A.; et al. Treatment of missing data determines conclusions regarding moralizing gods. PsyArXiv 2019, Preprint.

20. Slingerland, E.; Monroe, M.W.; Sullivan, B.; Walsh, R.F.; Veidlinger, D.; Noseworthy, W.; Herriott, C.; Raffield, B.; Peterson, J.L.; Rodríguez, G.; et al. Historians Respond to Whitehouse et al. (2019), “Complex Societies Precede Moralizing Gods Throughout World History". PsyArXiv 2019, Preprint. [CrossRef]

21. Savage, P. Additional Robustness Analyses Confirm that Complex Societies Precede Moralizing Gods throughout World History. Available online: https:/ / natureecoevocommunity.nature.com/users/233752-patrick-savage/posts/48583-additional-robustnessanalyses-confirm-that-complex-societies-precede-moralizing-gods-throughout-world-history (accessed on 26 February 2021).

22. Savage, P.; Whitehouse, H.; François, P.; Currie, T.; Feeney, K.C.; Cioni, E.; Purcell, R.; Ross, R.M.; Larson, J.; Baines, J.; et al. Reply to Beheim et al.: Reanalyses confirm robustness of original analyses. SocArXiv 2019, Preprint.

23. Whitehouse, H.; Francois, P. A Bad Time for (Some) Theories but a Good Time for History? Available online: http:/ / peterturchin. com/cliodynamica / a-bad-time-for-some-theories-but-a-good-time-for-history/ (accessed on 26 February 2021).

24. Beheim, B. Missing Data, Moralizing Gods, and the Siren Song of Aeiea. Available online: https://babeheim.com/blog/2019-0919-song-of-aeiea/ (accessed on 9 July 2021).

25. Slingerland, E.; Monroe, M.W.; Sullivan, B.; Walsh, R.F.; Veidlinger, D.; Noseworthy, W.; Herriott, C.; Raffield, B.; Peterson, J.L.; Rodríguez, G.; et al. Historians Respond to Whitehouse et al. (2019), “Complex Societies Precede Moralizing Gods Throughout World History". J. Cogn. Hist. 2020, 5, 124-141.

26. Whitehouse, H.; Turchin, P.; François, P.; Savage, P.E.; Currie, T.E.; Feeney, K.C.; Cioni, E.; Purcell, R.; Ross, R.M.; Larson, J.; et al. A New Era in the Study of Global History Is Born but It Needs to Be Nurtured. J. Cogn. Hist. 2020, 5, 142-158.

27. Turchin, P.; Whitehouse, H.; François, P.; Hoyer, D.; Alves, A.; Baines, J.; Baker, D.; Bartkowiak, M.; Bates, J.; Bennett, J.; et al. An Introduction to Seshat: Global History Databank. J. Cogn. Hist. 2020, 5, 115-123. [CrossRef]

28. Turchin, P.; Whitehouse, H.; François, P.; Hoyer, D.; Alves, A.; Baines, J.; Baker, D.; Bartkowiak, M.; Bates, J.; Bennett, J.; et al. An introduction to Seshat: Global History Databank. SocArXiv 2019, Preprint. [CrossRef]

29. Whitehouse, H.; François, P.; Savage, P.; Currie, T.; Feeney, K.C.; Cioni, E.; Purcell, R.; Ross, R.; Larson, J.; Baines, J.; et al. A new era in the study of global history is born but it needs to be nurtured. SocArXiv 2019, Preprint.

30. Turchin, P.; Whitehouse, H.; Larson, J.; Cioni, E.; Reddish, J.; Hoyer, D.; Savage, P.E.; Covey, R.A.; Baines, J.; Altaweel, M.; et al. Explaining the Rise of Moralizing Religions: A test of competing hypotheses using the Seshat Databank. SocArXiv 2019, Preprint. 
31. Beheim, B.; Atkinson, Q.D.; Bulbulia, J.; Gervais, W.; Gray, R.D.; Henrich, J.; Lang, M.; Monroe, M.W.; Muthukrishna, M.; Norenzayan, A.; et al. Treatment of missing data determined conclusions regarding moralizing gods. Nature 2021, 595, E29-E34. [CrossRef]

32. Whitehouse, H.; François, P.; Savage, P.E.; Hoyer, D.; Feeney, K.C.; Cioni, E.; Purcell, R.; Ross, R.M.; Larson, J.; Baines, J.; et al. Big Gods did not drive the rise of big societies throughout world history. OSF 2021. Preprint.

33. Vuong, Q.-H.; Bui, Q.-K.; La, V.-P.; Vuong, T.-T.; Nguyen, V.-H.T.; Ho, M.-T.; Nguyen, H.-K.T.; Ho, M.-T. Cultural additivity: Behavioural insights from the interaction of Confucianism, Buddhism and Taoism in folktales. Palgrave Commun. 2018, 4, 143. [CrossRef]

34. Vuong, Q.-H.; Ho, M.-T.; Nguyen, H.-K.T.; Vuong, T.-T.; Tran, T.; Hoang, K.-L.; Vu, T.-H.; Hoang, P.-H.; Nguyen, M.-H.; Ho, M.-T.; et al. On how religions could accidentally incite lies and violence: Folktales as a cultural transmitter. Palgrave Commun. 2020, 6, 82. [CrossRef]

35. Vuong, Q.-H.; Bui, Q.-K.; La, V.-P.; Vuong, T.-T.; Ho, M.-T.; Nguyen, H.-K.T.; Nguyen, H.-N.; Nghiem, K.-C.P.; Ho, M.-T. Cultural evolution in Vietnam's early 20th century: A Bayesian networks analysis of Hanoi Franco-Chinese house designs. Soc. Sci. Humanit. Open 2019, 1, 100001. [CrossRef]

36. Wilkinson, M.D.; Dumontier, M.; Aalbersberg, I.J.; Appleton, G.; Axton, M.; Baak, A.; Blomberg, N.; Boiten, J.-W.; da Silva Santos, L.B.; Bourne, P.E.; et al. The FAIR Guiding Principles for scientific data management and stewardship. Sci. Data 2016, 3, 160018. [CrossRef]

37. Costopoulos, A. Twilight of the Moralizing Gods: Lessons for a Better Academic World. Available online: https://archeothoughts. wordpress.com/2021/07/09/twilight-of-the-moralizing-gods-lessons-for-a-better-academic-world/ (accessed on 13 July 2021).

38. Savage, P. As Previously Mentioned, I Will not be Able to Continue Engaging Much on Twitter for Some Time, but Before I Step Back I'd Like to Emphasize Three Points I Hope We Can All Agree Upon. Available online: https://twitter.com/PatrickESavage/ status/1125194308045303808 (accessed on 1 July 2021).

39. Kavanagh, C. Think the Field Benefits From Having Major Publications Come Out in Top Tier Journals Addressing the Question. I Don't Think the Field Benefits from Bad Faith Sniping and Personal Insults. So I Look Forward to Reading More, but Hopefully with Less Unnecessary Invective. Available online: https:/ / twitter.com/C_Kavanagh/status/1125134869078536192 (accessed on 1 July 2021).

40. McElreath, R. It's All Made Much Worse by the Fact that the Missingness is So Extensive. Could Tell Any Story You Like with These Data, I Think. Plot. Available online: https://twitter.com/rlmcelreath/status/1171036709036994564 (accessed on 7 July 2021).

41. Cox, M.W. Zonal Marking: From Ajax to Zidane, the Making of Modern Soccer; Hachette UK: London, UK, 2019.

42. Wong, B. The mixer. Soccer Soc. 2018, 19, 630-632. [CrossRef]

43. Townsend, J. Rinus Michels and the Total Football Rebellion. Available online: https://thesefootballtimes.co/2016/01/28/rinusmichels-and-the-total-football-rebellion/ (accessed on 30 June 2021).

44. Gorynski, M. Is Total Football, the Holy Grail of the Modern Game, Still Alive in the Sport Today? Available online: https:// thesefootballtimes.co/2018/09/21/is-total-football-the-holy-grail-of-the-modern-game-still-alive-in-the-sport-today/ (accessed on 30 June 2021).

45. Vuong, Q.-H. The (ir)rational consideration of the cost of science in transition economies. Nat. Hum. Behav. 2018, 2, 5. [CrossRef] [PubMed]

46. Vuong, Q.-H. Reform retractions to make them more transparent. Nature 2020, 582, 149. [CrossRef]

47. Niehaus, A.C. Write fiction to discover something new in your research. Nature 2018, 557, 269. [CrossRef] [PubMed]

48. Physics Girl Physics Girl. Available online: https:/ / www.youtube.com/user/physicswoman (accessed on 1 July 2021).

49. Tibees Tibees. Available online: https:/ /www.youtube.com/channel/UC52kszkc08-acFOuogFl5jw (accessed on 1 July 2021).

50. Veritasium Veritasium. Available online: https:/ / www.youtube.com/c/veritasium (accessed on 1 July 2021).

51. Vsauce Vsauce. Available online: https://www.youtube.com/c/vsauce1/featured (accessed on 1 July 2021).

52. Scott, R. Blade Runner; Warner Bros.: Los Angeles, CA, USA, 1982.

53. Kubrick, S. 2001: A Space Odyssey; Stanley Kubrick Productions: London, UK, 1968.

54. IMARC Group Gaming Market: Global Industry Trends, Share, Size, Growth, Opportunity and Forecast 2021-2026. Available online: https: / / www.researchandmarkets.com/reports/5264066/gaming-market-global-industry-trends-share (accessed on 28 April 2021).

55. Kwok, R. Enterprise: Game on. Nature 2017, 547, 369-371. [CrossRef]

56. Coren, M.J. Fast Company Foldit Gamers Solve Riddle of HIV Enzyme within 3 Weeks. Available online: https://www. scientificamerican.com/article/foldit-gamers-solve-riddle/ (accessed on 28 April 2021).

57. Vuong, Q.-H.; Ho, M.-T.; Nguyen, M.-H.; Pham, T.-H.; Vuong, T.-T.; Khuc, Q.; Ho, H.-A.; La, V.-P. On the environment-destructive probabilistic trends: A perceptual and behavioral study on video game players. Technol. Soc. 2021, 65, 101530. [CrossRef]

58. Johnson, B. Hooked-Understanding Addiction through Art. Available online: https://socialsciences.nature.com/posts/39180hooked-understanding-addiction-at-science-gallery-london (accessed on 28 April 2021).

59. Ho, M.-T.; Hoang, K.-L.; Nguyen, M.-H.; Ho, M.-T. Chapter 8. The emerging business of science in Vietnam. In The Vietnamese Social Sciences at a Fork in the Road; Vuong, Q.-H., Tran, T., Eds.; De Gruyter: Warsaw, Poland, 2019; pp. 163-177. 
60. Tegmark, M. Our Mathematical Universe: My Quest for the Ultimate Nature of Reality; Random House: New York, NY, USA, 2014.

61. Vuong, Q.-H. Open Data, Open Review and Open Dialogue in Making Social Sciences Plausible. Available online: http://blogs.nature. com/scientificdata/2017/12/12/authors-corner-open-data-open-review-and-open-dialogue-in-making-social-sciences-plausible/ (accessed on 26 February 2021). 